\begin{tabular}{l} 
O P E R A T I O N S R E S E A R C H A N D D E C I S I O N S \\
\hline No. 3
\end{tabular}

DOI: $10.37190 /$ ord200307

\title{
THE LEVEL OF OMNICHANNEL USE IN POLISH MSMES
}

\author{
KATARZYNA SZYMCZYK* \\ Faculty of Management, Częstochowa University of Technology, \\ ul. Dąbrowskiego 69, 42-201 Częstochowa
}

\begin{abstract}
Nowadays, trade is shifting mainly to virtual reality. Increasingly more customers, using various types of mobile devices such as computers, smartphones, tablets, look for products and services in online stores, counting on fast, convenient and efficient fulfilment of the order. To meet the customers' requirements, trade enterprises may implement the omnichannel strategy as a way to streamline the entire sales and distribution system of goods from the store to the customer, ensuring the possibility of continuous monitoring transactions. The paper examines the development of omnichannel strategy by the Polish small and medium enterprises. The underlying assumption of the paper is to identify to what extent the Polish companies concentrate on omnichannel strategy in the functioning of their business. The discussion is based on the results of the study obtained from the CAWI survey, CATI survey, and the in-depth interview conducted among the group of Polish MSMEs in Silesian Voivodeship.
\end{abstract}

Keywords: omnichannel, multi-channel, management, company, strategy

\section{Introduction}

Managing the company requires multiple actions taken by the qualified managers and owners who, to establish the company's position on the market, should focus on verification of the marketplace, customers' expectations and desires while taking into account current achievements of competitors $[12,16]$. Such actions come to be a part of the process of scanning the business environment which should be done by owners and managers of companies lest to stay behind the others. Examining business surroundings is regarded nowadays as one of the most significant factors helping the business to obtain a better market position, to improve the financial condition, and to eliminate potential risks in retail. According to Urbanowska-Sojkin [18], business surroundings include all types of processes or phenomena which the company needs to take into consideration

*Email address: katarzyna.szymczyk@wz.pcz.pl

Received 13 January 2020, accepted 22 October 2020 
and learn how to react to their impact in terms of opportunities for business development or risk for the business to avoid. What takes place in the business environment becomes a collection of factors that influences the company's interaction with the customers and affects its business effectiveness in terms of sales success [9]. Therefore, the wider such environment, the more chances for the company's marketing success appear. The one who is focused on profits and development should implement the retail strategy which will gather more and more customers who will buy the offered products or services.

\section{Customers' role in a company's functioning}

According to Kotler [10], the company should regard the customers as a financial resource, which should be managed to become maximised as any other company's resource. Tiwana [17] categorises customers into three types:

- the most valued customers - MVCs, who contribute to the principal income of the company,

- the most growable customers - MGCs, who are most plausible to participate in the future income of the company,

- below zero customers - BZCs, whose value for the company becomes in the more extended period smaller than time, money, or resources invested in keeping them.

The primary aim of the company should be focusing on possessing MVCs and MGCs and reducing BZCs. Customers remain as an essential motivation for companies to function on the market and for the owners to run their business [5]. To acquire more and more satisfied customers, the company has to implement the adequate strategies of management and innovations that help to keep the customers and to obtain the new ones. Therefore, today there exists a strong inclination in management to organise the production and retail towards the effectiveness and flexibility, so the customers would be able to buy products and services easily, quickly, and in a way acceptable for them [11,3, 1, 2]. The task for the businessmen is not only to guarantee the quality and variety of their products but also to enable fast and comfortable purchasing. It is essential in terms of competitiveness and increasing customers' consciousness about the marketing rules. Today the customer is aware of what (s)he needs, wants to buy, or which products are superfluous. The more the customer trusts the company, the more benefits in sales they bring, as they become the actual loyal purchasers who pay for the products and services $[20,8]$. What may help the retailers to keep the customers and guarantee their satisfaction with shopping is the variety of channels of purchasing [1]. In this case, the company should consider the implementation of IT solutions in sales management to enable the customers to reach the offered products through different tools. It includes physical shops and online shopping. The question arises whether the company uses the single, or multi- 
-channelled retail, or they choose the most advanced way of trading, namely the omnichannel strategy in their sales management.

\section{The multi-channel vs. omnichannel approach in business strategy}

Each retailer decides on the choice of ways to reach the customers. The easiest way is probably to open a shop and wait for the clients. It is the single-channel retailing which for a long time was the only way of running business available on the market. Due to the increasing competitiveness as well as the development of information technology, such a model has rapidly changed, and more options of selling have become obtainable. Retailers have started to promote their businesses in media or use the computer as the tool to interact with customers. Such methods enabled differentiation of channels through which the customers could learn what products are offered. This socalled multi-channel strategy let the retailers obtain more customers. The multi-channel strategy includes the whole variety of channels which are:

- traditional, such as store location, an advert in the newspaper, printed banner, an event promoting the sale, etc.,

- digital, such as website, email, mobile application, or SMS messaging [15, 14, 7, 2].

Channels available to the customer but not connected

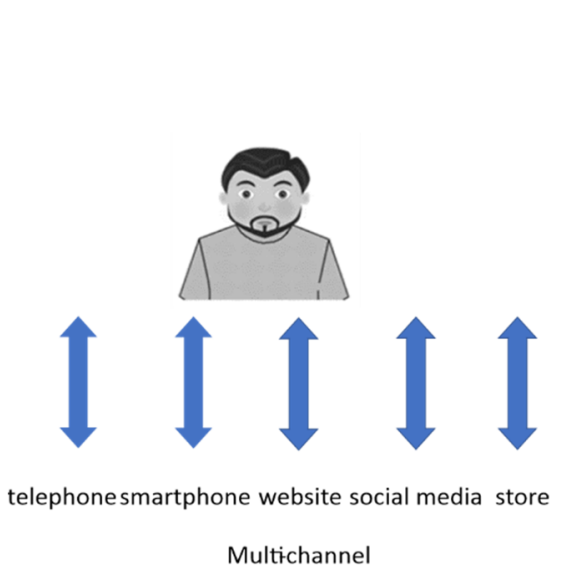

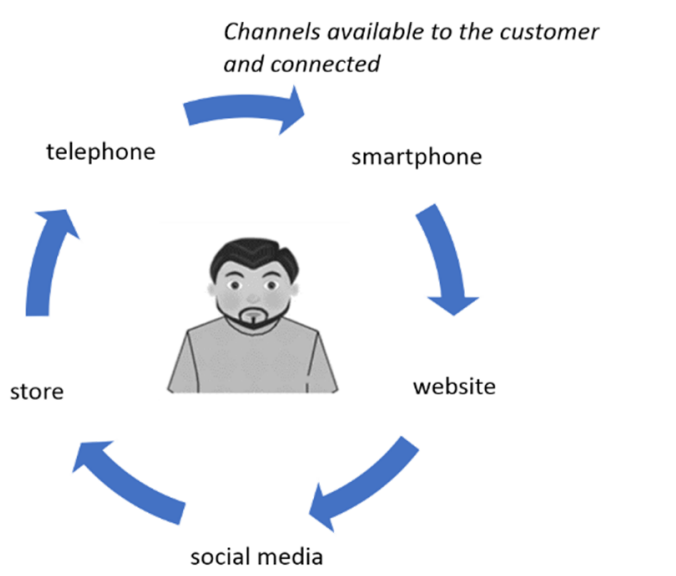

Omnichannel

Fig. 1. The difference between the multi-channel and the omnichannel approach

The implementation of a multi-channel strategy, according to Bauer [4], is the biggest challenge for the retailing companies. It combines the traditional stationery selling with online commerce which together may increase the loyalty of the customer and their likelihood to buy the product. One of the essential benefits of the strategy is that the 
customer can look for the information about the product in a traditional store, or, at the same time, can obtain additional information online by using mobile devices. It enables the customer the comparison of the offers and prices [19,1]. Nevertheless, this approach does not include feedback from the customer who can bring more information about the customer's behaviour. Therefore, the multi-channel strategy has been improved into the omnichannel approach in retailing. It becomes the strategy of a complete, fully integrated package of tools and tasks to approach the customers [19]. The omnichannel approach improves communication with the customer, enables the retailer to learn their lifestyle and needs about the product and brands. As a whole, it expands the variety of channels and includes the interaction between the retailer and the customer $[13,6,7]$. Furthermore, the omnichannel approach allows for the integration of promotion and selling campaigns together with social media, and the customer switches the devices to get the same coherent information. The flow of this information is constant and continued, as well as smooth [13]. The difference between the multi-channel and the omnichannel approach in the management of the company is illustrated in Fig. 1.

As the above illustration presents, the fundamental distinction in the omnichannel approach assumes that all channels which are available to the customer are fully connected and integrated, whereas in the multi-channel strategy, the customer can choose from the open channel, but these are not connected and the flow of information in them is regarded as separate. The problem for the company is to decide which approach the company should select in terms of raising the approach to customers. The following study carried out among the Polish companies shows what types of goods and services, as well as the scale of functioning, influence the company's decision about selecting the channels of marketing and distribution of products to the customers.

\section{Methodology and research findings}

The paper aims to find out if the omnichannel strategy is used by Polish micro, small, and medium companies. To achieve the purpose of the study, the author conducted a scientific study which involved 64 entities: micro firms, small, and medium companies that operate in Silesian Voivodeship. The research sample included different forms of business: production, retail, and/or service. The author assumes, hypothetically, that the omnichannel strategy can be beneficial for every sector and every business. She believes that ITC technology is nowadays an indispensable part of business management, regardless of the sector, and the omnichannel can make such management faster and more effective. Therefore, the study was addressed to randomly chosen companies to examine if they follow the technological integration of channels to successfully communicate with customers. The present study may be considered a preliminary 
study. The obtained results supplement the current research and can also be used for comparisons in subsequent examinations.

For a better discussion of the study results, the author divided the research sample into two groups, according to the types of methods used, i.e., quantitative and qualitative:

- group A (53 entities): a quantitative survey based on the questionnaire with the use of CATI and CAWI,

- group B (11 entities): an in-depth interview based on the questionnaire with open and closed-ended questions.

Group A includes $70 \%$ of companies which operate only on the domestic market, $28 \%$ of companies which function both on the mother and foreign markets, and $2 \%$ of the companies operate only on international markets. The entities that operate in various business sectors which are presented in Fig. 2.

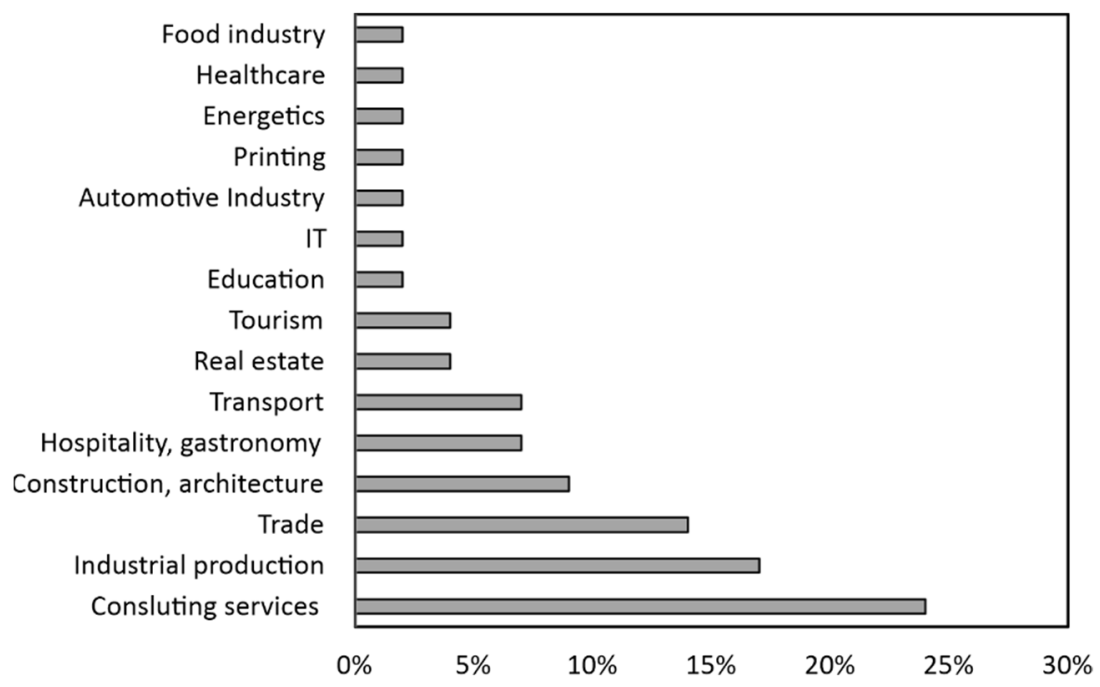

Fig. 2. Types of the business sector of companies in SMEs, group A $(N=53)$

The survey reveals that most companies in the study offer services and consultancy (24\%), other companies do industrial production (17\%), commerce (14\%), and $9 \%$ operate in building and architecture sector. There are 7\% of entities which run hotels and restaurants, and $7 \%$ of the companies operate in the transport sector. In group A, 89\% of companies operate on the market in a form that requires direct contact with the customer. $56 \%$ of companies only sell services, $9 \%$ combine trade and services, $8 \%$ combine production, trade, and services, $4 \%$ of companies produces and services companies, $9 \%$ of companies run retail sales, and $3 \%$ are production and trade firms. $11 \%$ of com- 
panies are production entities that generally do not maintain direct contact with the recipient of the goods, but contact contractors who mediate in the sale of the products between the producer and the customer.

Generally, it can be assumed that if $89 \%$ companies operate on the market in a form that requires direct contact with a customer, they should consider introducing the adequate strategies and/or actions in the retail management which would help to achieve and maintain a better relationship with the client. Such activities should not only attract the clients and seize them but also work out several channels through which the company can reach new customers and maintain contact with them. In the survey, it was verified that companies focus on the price effect in attracting the customers $-58 \%$ of companies try to offer products and services cheaper than other ones so that they can gather more clients than a competitor in the market. 53\% focus on developing various activities to attract new customers and $47 \%$ of companies consider it necessary to meet the requirements and customer expectations, mainly if customer groups belong to a particular niche. $38 \%$ try to offer products to entirely new customer segments, and $34 \%$ of companies pay attention to the introduction of new products or services to broaden the spectrum of the company's offer and attract more customers. $24 \%$ of the surveyed companies admit that they attract the customers by offering additional benefits from the implementation of sales.

To build retail channels to reach customers, the companies (group A) use specific resources. $72 \%$ of companies hire qualified staff that manages the entire product delivery to the customers and analyses their opinions. $47 \%$ use IT tools in sales management and $45 \%$ base sales success on the use of mobile devices and software. $36 \%$ of the surveyed companies generally prefer direct contact with customers through retail stores, warehouses, and the company's office.

The companies were also asked to indicate which resources they find most and least important in the process of building channels with the customers. The answers received from the companies suggest that the staff is very much significant for the entities in the process of building and, in the future, maintaining the channels to interact with the customers. However, equally important are software and IT tools, especially in comparison to the company's infrastructure. They may support the assumption that the companies follow the present trends in management, which is to a great extent based on innovative information technology. Therefore, it is worth analysing to what extent the companies implement the multi-channel and the omnichannel approach.

For a more profound examination whether the companies base their retail management on the multi-channel or the omnichannel strategy, the direct interview was conducted among 11 entities (group B) of small and medium-size. The following results refer to the selected group of MSMEs. The first aim of the interview was to identify the actions taken to build the channels to reach and obtain the customers both in domestic and foreign markets. The companies pointed out that their expansion in international markets resulted from the need for acquiring new customers for goods and services and 
gathering more income. Therefore, some of the actions the companies took to approach foreign customers. The results are presented in Fig. 3.

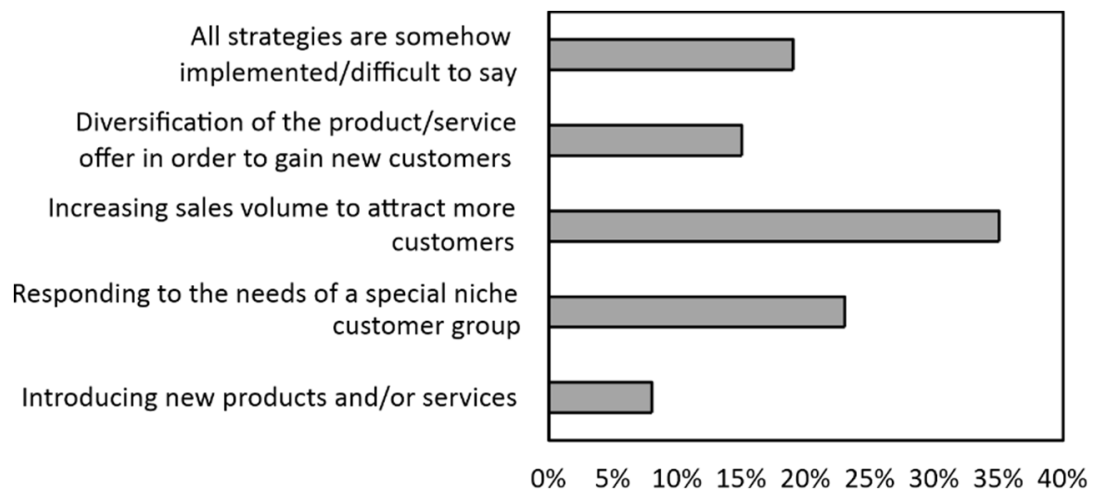

Fig. 3. Actions taken by group B to enable customer acquisition $(N=11)$

The majority (35\%) increase the sale of goods on foreign markets due to the former analysing of the market in terms of the demand and customers' preferences. $23 \%$ are prepared to address the offer of products and services to the specific, niche group, whereas, $15 \%$ are aware of the fact that developing and diversification of actions taken inside the company leads to enriching the offer, which can contribute to obtaining new customers. Asked about the channels to approach the customers, the companies enumerate all types of them, which eventually leads to identifying the strategy in retail management in terms of its multi- and omni-assumptions. All the answers are gathered and presented in Table 1. During the interview, the companies were asked to indicate what channels they use to gain more customers, both on domestic and foreign markets. According to the collected answers, the majority of the companies owns physical stores, offices or production plants, and they support their business with an adequate website. The contact with the potential customers is done by traditional, landline telephone or mobile phone, additionally, some of the companies still use fax. The companies neither provide smartphone application for the customer nor run social media like Facebook, Twitter or Instagram to enable fast communication and mobile shopping.

Only 4 out of 11 questioned entities have an online shop where the customers can purchase goods. Generally, customer service is somewhat limited and not integrated. The companies in majority admit knowing different modern channels to communicate with the customers like social media, for example, however, they, at the same time, highlight the specificity of their business which includes the retail of goods for further exploration, and thus the customers belong to the group that purchases products in wholesale quantities. Such retail does not require social media or applications because it is based on long-term distribution contracts and requires detailed discussion between the customer and the company. The customers buying goods in relatively small quantities 
for use or consumption are in minority. Therefore, the implementation of the omnichannel approach in retail, according to the research results, might be more useful for companies which focus on the retail of small goods for everyday consumption and entertainment.

Table 1. Channels to approach the customers by MSMEs, group $\mathrm{B}(N=11)$

\begin{tabular}{|c|c|c|c|c|c|c|c|c|}
\hline \multirow[b]{2}{*}{ Firm } & \multirow[b]{2}{*}{ Size } & \multirow{2}{*}{$\begin{array}{l}\text { Business } \\
\text { form }\end{array}$} & \multicolumn{6}{|c|}{ Channels } \\
\hline & & & $\begin{array}{c}\text { Physical } \\
\text { store }\end{array}$ & Website & $\begin{array}{l}\text { Online } \\
\text { store }\end{array}$ & $\begin{array}{c}\text { Smartphone } \\
\text { application }\end{array}$ & $\begin{array}{l}\text { Social } \\
\text { media }\end{array}$ & Telephone/fax \\
\hline $\mathrm{A}$ & micro & $\begin{array}{l}\text { production } \\
\text { trade } \\
\text { service }\end{array}$ & yes & yes & no & no & no & yes \\
\hline B & middle & $\begin{array}{l}\text { production } \\
\text { trade }\end{array}$ & yes & yes & yes & no & no & yes \\
\hline $\mathrm{C}$ & small & $\begin{array}{l}\text { production } \\
\text { trade }\end{array}$ & no & yes & no & no & no & yes \\
\hline $\mathrm{D}$ & middle & $\begin{array}{l}\text { production } \\
\text { trade }\end{array}$ & no & yes & no & no & no & yes \\
\hline $\mathrm{E}$ & middle & $\begin{array}{l}\text { production } \\
\text { trade }\end{array}$ & yes & yes & yes & no & no & yes \\
\hline $\mathrm{F}$ & small & $\begin{array}{l}\text { production } \\
\text { trade }\end{array}$ & yes & yes & yes & no & no & yes \\
\hline G & middle & $\begin{array}{l}\text { production } \\
\text { trade } \\
\text { service }\end{array}$ & yes & yes & yes & no & no & yes \\
\hline $\mathrm{H}$ & middle & $\begin{array}{l}\text { production } \\
\text { trade } \\
\text { service }\end{array}$ & yes & yes & no & no & no & yes \\
\hline I & middle & $\begin{array}{l}\text { production } \\
\text { trade } \\
\text { service }\end{array}$ & yes & yes & no & no & no & yes \\
\hline $\mathrm{J}$ & middle & $\begin{array}{l}\text { production } \\
\text { trade }\end{array}$ & yes & yes & no & no & no & yes \\
\hline $\mathrm{K}$ & middle & $\begin{array}{l}\text { production } \\
\text { trade }\end{array}$ & yes & yes & no & no & no & yes \\
\hline
\end{tabular}

A - musical toys and instruments, $\mathrm{B}$ - toys and blocks, $\mathrm{C}$ - shoemaking, D - automotive industry, $\mathrm{E}$ - window decorations, $\mathrm{F}$ - plastic components for cars, $\mathrm{G}$ - lamps/lighting, $\mathrm{H}$ - footwear components, $\mathrm{I}-$ steel industry elements, $\mathrm{J}$ - car links, $\mathrm{K}$ - metal components.

\section{Conclusions}

- Most companies in the study prefer physical stores, offices or production facilities and, additionally, they provide a company website. 
- Companies in the study use a landline or mobile phone to contact potential clients and they do not provide applications for smartphones or run social media such as Facebook, Twitter or Instagram.

- Several companies in the study have an online store.

- The specificity of the business, which includes retail sales of goods for further exploration, means that customers belong to the group that buys products in bulk quantities.

- Customers who purchase goods in relatively small amounts for everyday use, consumption or entertainment, are a minority.

- Purchases are based on long-term written distribution agreements and require a detailed face-to-face discussion between the customer and the company, not via social media or smartphone applications, but in person or by email.

- Large-scale companies operating on foreign markets may consider the omnichannel strategy in retail to be more beneficial in terms of direct control and information flow.

- Customer service is somewhat limited and not integrated.

- Business specificity of the majority of the surveyed companies does not require the omnichannel approach.

- The surveyed companies have not implemented the omnichannel strategy and they rely on the multi-channel approach which is practised since the launching of companies.

The companies in their trade strategies should search for the most effective ways to interact with the customer and satisfy her or his requirements and preferences. It is a critical factor in increasing retail and building the status of the company on the market. Additionally, for those who operate in foreign markets, the contact with the customer must be done by IT tools to be actual and efficient. For such companies, therefore, the omnichannel appears to be the most adequate, as they can fully control the flow of information form the customers and learn about their preferences and needs. The integration of different channels, in such a case, might improve the retail and strengthen the position of the company on the market. Yet, as the study results show, some of the companies which produce, sell, and provide service on a big scale, or their goods are meant to be sold in significant amounts, appear to be less inclined to implement the variety of channels, apart from the necessary IT tool such as the website. In this case, contact with the customer is rather simple and based on telephone or mobile phone calls, emails, or communication in physical stores. The multi-channel approach is, in this case, more frequently spotted.

\section{References}

[1] Antonowicz M., Omnichannel strategy - a challenge for logistics, Handel Wewn., 2017, 5, 14-23 (in Polish). 
[2] ANTONOwicz M., Internet commerce - implications for logistics, Handel Wewn., 2016, 2, 5-16 (in Polish).

[3] BARna M., POPA V., Consumer and shopper satisfaction. Measurement of collaborative supply value chain, Supply Chain Manage., 2011, 2 (1), 39-47.

[4] BAuer A.W., Online oder offline? Der Handel im Spannungsfeld zwischen Old und New Economy - Die Zukunft gehört dem Multi-Channel Retailer, [In:] D. Ahlert, J. Becker, P. Kenning, R. Schütte (Eds.), Internet \& Co. im Handel. Strategien, Geschäftsmodelle, Erfahrungen, Berlin 2001, 51-62 (in German).

[5] Gudkova S., Small business development. Knowledge, personal connections, learning process, Wydawnictwa Akademickie i Profesjonalne, Warszawa 2008 (in Polish).

[6] HÜBNER A., KUHN H., WOLlENBURG J., Last mile fulfilment and distribution in omni-channel grocery retailing, Int. J. Ret. Distr. Manage., 2016, 44 (3), 228-247.

[7] KaWA A., Shaping customer relationships in multi-channel integrated trade, Org. Kier., 2017, 2, 285-298 (in Polish).

[8] KorZeniOwsKi L.F., Management. Management basics, EAS, Cracow 2010 (in Polish).

[9] KosIŃsKa E., International marketing. Outline of issues, PWE, Warsaw 2008 (in Polish).

[10] KotLer P., Marketing from A to Z, PWE, Warsaw 2004 (in Polish).

[11] Marquardt K., Agile. A new approach for quality improvement initiatives within customer service, Supply Chain Management, 2016, 7 (1), 106-118.

[12] Melacini M., TAPPIA E., A critical comparison of alternative distribution configurations in omni-channel retailing in terms of cost and greenhouse gas emissions, Sustainability, 2018, 10, 307.

[13] Rowell J., Omni-channel retailing, Romanian Distr. Comm. Mag., 2013, 4 (2), 12-15.

[14] Schierholz R., Glissmann S., Kolbe L.M., Brenner W., Don't call us, we'll call you. Performance measurement in multi-channel environments, J. Inf. Sci. Techn., 2006, 3 (2), 44-61.

[15] Solomon E.A.C., STANley O.A., Success O.E., Nelson A.E., Trade fairs and marketing performance in the Nigerian manufacturing industry, Plat. Res. J. Bus. Manage., 2017, 1 (3), 15-23.

[16] STRUŻYCKI M., Business Management, Difin, Warsaw 2004 (in Polish).

[17] Tiwana A., Knowledge Management Guide. E-Business and CRM Applications, Placet, Warsaw 2003 (in Polish).

[18] UrbanowsKa-Sojkin E., Strategic Enterprise Management, PWN, Warsaw 2004 (in Polish).

[19] Verhoef P.C., KANNAN P.K., InMAN J.J., From multi-channel retailing to omni-channel retailing: Introduction to the special issue on multi-channel retailing, J. Ret. Multi-Chan. Ret., 2015, 91 (2), 174-181.

[20] WóıcıK K., Public Relations from A to Z, Placet, Warsaw 1997 (in Polish). 